\title{
Realigning Vertical Dance on a Horizontal Continuum
}

\author{
By Danielle K. Garrison*
}

\begin{abstract}
How and by whom does a relatively new art form, such as aerial dance, become validated in the current United States? King Louis XIV birthed a model upon which Western dance has depended upon to answer this question since 1661. Louis XIV essentially established an aesthetic split between the verticality of ballet and the curvilinear quality of acrobatics, causing a hierarchical binary to form in ballet's favor. This hierarchical aesthetic split between dance and acrobatics currently exists in the US between the genres of aerial dance and aerial circus. I am claiming that leading US aerial dance practitioners are rewarded through the language of art critics, support of funding organizations, and placement within academia for aligning their work with the ballet lineage aesthetics rather than circus acrobatics, which is influencing the artistic evolution of the aerial dance genre.
\end{abstract}

How and by whom does a relatively new art form, such as aerial dance, become validated in the current United States? King Louis XIV birthed a model upon which Western dance has depended upon to answer this question since 1661. By creating the Académie Royale de Danse, King Louis XIV essentially established an aesthetic split between the verticality of ballet and the curvilinear quality of acrobatics, causing a hierarchical binary to form in ballet's favor. This hierarchical aesthetic split between dance and acrobatics currently exists in the United States (US) between the genres of aerial dance and aerial circus. I am claiming that leading US aerial dance practitioners are rewarded through the language of art critics, support of funding organizations, and placement within academia for aligning their work with the ballet lineage aesthetics rather than circus acrobatics, illuminating a predisposed "high art" validation embedded within dance aesthetics and upheld by artistic "gatekeepers". I will investigate how the validation of aerial dance is determined through US artistic "gatekeepers" such as academia, funding organizations, and critics. In particular, how the notion of critical assignation of a superior "quality" via the language constructs shaped by binaries set apart in 1661, in dialogue with funding and academia, is influencing the artistic evolution of the aerial dance genre.

In order to decompact this complex thesis, I will first provide a brief genealogical abstraction of the history of aerial circus, aerial dance, and ballet. Next, I will discuss the modern triangular relationship between theses genres.

* MFA Dance Candidate-Aerial Dance Track, University of Colorado, Boulder, USA. 
Finally, I will analyze a case study with Aerial Dance Chicago to demonstrate the idea of dance aesthetics validating the aerial dance genre. This examination of the aerial dance genre is imperative due to a limited amount of scholarly work written on the field. I will present new research on the aerial dance genre, and initiate a more complex dialogue regarding how aerial dance is validated. It is important to provide more research into this growing international dance field and to fearlessly study a genre in the midst of becoming an established art form.

For the purpose of this paper, I will use the term "dance" to encompass ballet and Western concert dance that derived from either emulation of or resistance to ballet in order to focus on the aesthetic hierarchical lineage set forth by King Louis XIV. "Aerial arts" encompass all aerial work. "Aesthetic(s)" are defined as the thematic and definitive visual appearance of an art form. For this paper, "high art" connotes a cultural value of an art form given by a person or group in power, including but not limited to critics, funding organizations, and higher education establishments. Whereas, "low art" will refer to art that is considered "popular" or entertainment. This paper is not intending to make a personal judgment on the differentiations between "high" and "low" art, but rather to reveal the cultural implications and empirical reality of this schism present in Western art and upheld by US "gatekeepers".

\section{Histories}

It is fair to begin with the history of aerial circus since it is a genre born one century ahead of aerial dance. In The Ordinary Acrobat, Duncan Wall depicts the history of the circus genre and illustrates that the first type of physical theatrics involved acrobatics. ${ }^{1}$ Acrobatics eventually evolved into the official circus proper in 1768 and was mostly a familial trade. ${ }^{2}$ Wall also narrates the history of aerial circus, which is one discipline within the circus genre that focuses on acts performed with aerial apparatuses. Aerial circus first took flight in Paris with the debut of the flying trapeze developed by Jules Léotard in $1859 .{ }^{3}$ While sitting by a pool, Léotard came up with the idea to swing from a chin up bar and drop into a pool. Voilà, the invention of the first aerial apparatus, the high-flying trapeze.

The spectacle of the trapeze act has evolved over the century, and contemporary French circus groups, such as Les Arts Sauts, perform "aerial ballets", which are "poetic, open-air spectacles staged above an audience and

\footnotetext{
1. Duncan Wall, The Ordinary Acrobat (New York: Vintage Books, 2013), 30.

2. Ibid., 4 .

3. Ibid., 155.
} 
consisting almost entirely of trapeze". ${ }^{4}$ Aerial circus focuses on performing tricks in various aerial apparatuses, such as the trapeze, fabric, and lyra, and is often described by viewers, critics, and circus performers as acrobatic, thrilling, entertaining, skillful, and risky. The history of the circus is too complex and significant to condense appropriately for the purpose of this paper. In short, the history of the circus has had its ups and downs over the last century, especially in the US where it has primarily been viewed as entertainment and struggles to be seen as an art.

The first aerial dance apparatus was a modified version of the first aerial circus apparatus, yet was created in rebellion of the circus genre. In an interview I had with the credited founder of aerial dance, Terry Sendgraff, she expressed she was in search of something "truer" for herself than ballet, modern dance, gymnastics, and circus could provide. Sendgraff found inspiration in post-modern and improvisational dance and used principles found in these movements to create the distinct genre of aerial dance. ${ }^{5}$

The history of the aerial dance genre begins in the 1970s in a little studio in Berkeley, California called Skylight Studio (latter known as Motivity Center for Aerial Dance). Terry Sendgraff was teaching a student on a double point trapeze that she set up low enough to the ground that one could reach from standing. The student started to spin, and thus wound-up the trapeze ropes. At that moment, Sendgraff thought about inventing the first single point trapeze. She decided to rig a single point trapeze and premiere this new apparatus on a proscenium stage in 1976, and thus begins the official flight of the aerial dance genre. ${ }^{6}$ Nancy Smith and Jane Bernasconi, co-authors of the first book on aerial dance titled Aerial Dance, define the genre as: "anything that lifts a dancer off the ground with an apparatus such as a trapeze".7

Experimental aerial work had been performed by different artists of the post-modern dance era, but the authors claim Sendgraff birthed the lineage of the genre because her work included the intention of refining the art of aerial dance rather than containing aerial work to enhance a dance piece.

Sendgraff has a movement history in both gymnastics and dance. She received her Master of Fine Arts degree in dance from the University of Colorado Boulder (CU-Boulder). In Denver, she briefly experimented with a flying trapeze rigged 40 feet high, but was not very keen on studying it since she "could not dance with or on it" and "left the circus thing". ${ }^{8}$ She went on to teach ballet and modern dance at Arizona State University (ASU). At ASU she

4. Ibid., 153.

5. Terry Sendgraff, telephone interview by Danielle Garrison, November 13, 2014.

6. Jayne C. Bernasconi and Nancy E. Smith, Aerial Dance (Champaign: Human Kinetics, 2008), 12.

7. Bernasconi and Smith, Aerial Dance, 5.

8. Sendgraff, telephone interview. 
presented work that was humorous, acrobatic, and clownish, but it was not well received by the "higher-ups" in fine arts academia. ${ }^{9}$ She decided not to go the acrobatics route again in choreography. Sendgraff was not only artistically conditioned by the negative response of her superiors at ASU, but also by her ballet and modern training at CU-Boulder, which was viewed by academia as the appropriate artistic forms of expression. Sendgraff felt that in order for her work to be taken seriously, she needed to stray away from circus aesthetics and utilize dance aesthetics. ${ }^{10}$

Sendgraff voiced in the interview that she always had a disdain towards circus, even when first experimenting with the high-flying trapeze in Denver. Sendgraff did not reject circus aesthetics solely because of outside influences; she personally was not fond of the "tricks, focus on technique, flashiness, and phoniness in circus ... and even though circus could execute tricks beautifully, it did them the same way all the time". ${ }^{11}$ Sendgraff thought art should fulfill a higher purpose than just entertainment. She wanted to do her own work that was "authentic, organic, different, and not focused on thrill", and coined her aerial dance technique motivity, which was influenced by her academic dance experience as well as the post-modern and improvisational dance movements. ${ }^{12}$

The notion of ballet and modern dance being "acceptable" mediums of performance and acrobatics being scolded in academia is a testimony to the resonation of King Louis XIV's hierarchical aesthetic split between dance and acrobatics. According to Jennifer Homans, a dance scholar who has written on the origins of ballet in Apollo's Angels, dance became an academic pursuit through the opening of the first academy of dance, of which acrobatics were excluded..$^{13}$ Even though dance has not always been accepted as a worthy scholarly pursuit, it is slowly being seen as a valuable "text" to be studied within US academia. Aerial dance is now part of the graduate dance program at CUBoulder, coincidentally, the school Sendgraff attended. CU-Boulder is offering the first graduate aerial dance track program in the US, and a place within academia provides grant funding opportunities, salaried teaching compensation, research support, and networking, all of which will enhance the validity of the aerial dance genre. Circus does not yet have a place within a graduate level university program in the US. So, how did ballet become regarded as a more valid aesthetic than acrobatics within Western art?

The origins of ballet were unfolding in Florence, Italy during the Renaissance. The revival of Platonic thought that dominated Florence during

\author{
9. Ibid. \\ 10. Ibid. \\ 11. Ibid. \\ 12. Ibid. \\ 13. Jennifer Homans, Apollo's Angels (New York: Random House, 2010), 16.
}


the Renaissance was tangibly present in the Florentine Platonic Academy, which practiced Neoplatonism. ${ }^{14}$ The embodiment of the Neoplatonic ideals of verticality, symmetry, beauty, and a connection to the divine was being portrayed within significant Renaissance art through the depiction of the human body. Homans claims that Charles IX, who ruled France about a century before King Louis XIV, established the Neoplatonic Académie de Poésie et de Musique "modeled after the famous Renaissance Florentine Academy" and believed dance "might break some of the earthly ties and raise himself up, closer to the angels". ${ }^{15}$ Humanism was being explored in the Renaissance, and therefore, the fascination with artistically expressing the human form was dominant in art and emulated through embodiment by the elite members of society. Renaissance artists, such as Botticelli, Michelangelo, and Bosch, were part of a larger movement that illustrated the vertical ascendance of earthly images to portray Neoplatonic ideals of beauty. For example, Botticelli's Primavera depicts idealized forms of women in the contrapposto position that emulates the classical vertical Greek body position. Rab Hatfield, a Botticelli Art Historian, cites Kenneth Clark's comment considering the three dancing girls in Primavera as "one of the most personal and memorable evocations of physical beauty in the whole of art ... [the dancers] are light-foot[ed] ... and danced before the other gods". ${ }^{16}$ These dancers appear unbound by gravity, and represent an ideal beauty that connects earth to a higher realm. Homans explains that under the absolutist reign of the Sun King, Louis XIV, dancers "were well proportioned and graceful ... [and] physical appearance was taken to be a sign of inborn nobility". ${ }^{17}$ Homans continues to elucidate that under Louis XIV: ... the emergence of classical ballet as a fully articulated theatrical art ... became much more than a blunt instrument with which to display royal opulence and power. He made it integral to life at court, a symbol and retirement of aristocratic identity. ${ }^{18}$

Ballet was necessary to achieve higher social status and Louis XIV stated "the art of dancing ... is most advantageous and useful to our nobility". ${ }^{19}$ Art and dance were purposed to enhance the nobility with a "higher" quality than seemed achievable on earth; the goal of etherealness that was beyond the common human. In ballet, through the vertical alignment of the spine, reverence offered to the King connotes religious and authoritative symbolism,

14. Homans, Apollo's Angels, 5.

15. Ibid., 5-6.

16. Rab Hatfield, "Some Misidentifications in and of Works by Botticelli," in Sandro Botticelli and Herbert Horne New Research, ed. Rab Hatfield (Florence: Syracuse University Press, 2009), 9.

17. Homans, Apollo's Angels, 17.

18. Ibid., 12.

19. Ibid., 15. 
both which connected and embodied Louis XIV's power to divine rule. In Making an Entrance Adam Benjamin claims:

... the rulers of Christendom would refer back to classical ideals particularly when they needed to reinforce a political message (from on high). No one did this more effectively than Louis XIV ... [and ballet was] attempting to display the distance between [royalty] and common people who lived on a from the Earth. Dis stance, quite literally - a different standing. The purpose of courtly dance was specifically to establish and physically mark as different those who lived closer to the gods. ${ }^{20}$

Dance permitted the nobility to embody Christian ideology, and could literally raise the elite members of society to a more elevated status.

The intention of ballet was considered a more "serious", "proper", "elite", and "purposeful" study than acrobatics in Louis XIV's court. During the early seventeenth century, acrobatics emphasized spectacle, were not part of an academic structure of training, and were "occupied by a low social caste". ${ }^{21}$ The curvilinear aesthetic of acrobatics, potentially as seen by Louis XIV, was too "low art" or less "purposeful" than ballet. The verticality of dance was constructed to be superior to acrobatics; dance was an art, not just a craft. ${ }^{22}$ Even though a craft requires skill and technique, art has a more erudite purpose connecting to religious and political power. This aesthetic hierarchical split between dance (art) and acrobatics (craft) created a "high" and "low" art division in Western performance and continues to inform the validity of performance arts in the US.

Through the retracing of the history of each genre, it can be understood that each has strong, yet, interconnected roots. Given that the verticality and theatrical intention of ballet has summoned political and aesthetic power in the Western world since the Renaissance, I aim to show that current US aerial dance and circus practitioners gain validation by aligning their work with ballet-derived dance aesthetics.

\section{Modern Trifecta}

For this section of the paper, I want to articulate my recognition that every artist evolves, and that each artist I discuss is continuing to uncover their genuine artistry. However, my argument includes the particular lens that investigates the compelling gravitational pull of tradition and its lasting

20. Adam Benjamin, Making an Entrance: Theory and Practice for Disabled and NonDisabled Dancers (London: Routledge, 2002), 26.

21. Wall, The Ordinary Acrobat, 44.

22. Homans, Apollo's Angels, 16. 
effects currently at work in US arts, specifically in shaping the aesthetic direction of the young genres of aerial dance and contemporary circus, which are seeking establishment.

Leading contemporary aerial circus practitioners in the US, such as Shayna Swanson, are redefining the circus genre by emulating France's "nouveau cirque" movement, which does not involve animals and employs a theatrical, character-based approach, as well as thematic elements of ballet and aerial dance. Swanson is the founder of Aloft Circus Arts (Aloft) in Chicago as well as the Chicago Contemporary Circus Festival and artistically displays the shift in aesthetics that US contemporary circus is undergoing. Swanson defines Aloft's artistic intention as:

... a collection of earth-bound aerial and circus artists, expressing ourselves without regard to gravity. Aloft reveals more than just the splendor and danger inherent in our art; we construct accessible, purposeful stories, drawing on the juxtaposition of artistic, emotional and physical extremes, and let them loose anywhere between the ground and the sky. The results are acts and full-length productions that are powerful, dangerous, hilarious and passionate; where spectacle lies not in special effects or elaborate sets, but in the intensity, beauty and captivating nature of the human body entwined in circus. ${ }^{23}$

This description that combines the "spectacle" often associated with circus in the US with an artistic intention proposed by a storyline, is not a common element of US circus. In the US, circus is often epitomized as the Ringling Brothers Circus, and is therefore associated with animal performances, stunts, and distinct acts, all of which were characteristics of French circus prior to the nouveau cirque movement. By acculturating attributes of the nouveau cirque movement, ballet, and aerial dance to make cohesive evening-length circus work, Swanson is distancing Aloft, and the identity of US contemporary circus, from the longstanding US circus motif. Swanson sees circus as a profound entertaining art form, and is walking a tightrope between entertainment and "high art" while trying to find a balance or unification between the two. ${ }^{24}$ As circus in the US struggles to be seen as an art, and not merely a form of entertainment, Swanson contends it can be both. Aloft actually identifies as both aerial circus and aerial dance through two distinct websites promoting each identity. ${ }^{25}$ The purpose of Aloft Circus Arts having an aerial dance identity could be to elevate the status of her circus company by

23. "Aloft," Aloft Circus Arts, accessed September 27, 2014, http://goo.gl/qNlCtF.

24. Ibid.

25. "Aloft Circus Arts," Aloft Circus Arts, accessed November 1, 2014, http://goo.gl/1spp3Y. 
partly identifying as dance; the circus identity is for entertainment and the aerial dance identity is for a more culturally-sanctioned artistic image.

Circus not being viewed as a legitimate art is a problem in the US, but not in France, where circus is a highly valued art form. Duncan Wall claims that over 150 circus schools thrive and are amply funded by the French government. ${ }^{26}$ Circus in France is seen and funded as an art, receiving over 9 million euros per year from the government. ${ }^{27}$ Circus was not always valued in France; in the early 1980s, a government initiative funding program was started to support not just "high culture, but popular forms as well", including the almost deadened art of circus. ${ }^{28}$ US funding establishments are resistant towards supporting "popular arts" such as circus, as will be discussed later in this paper. But, it is crucial to note that Aloft Circus Arts is a for-profit company, whereas, most leading ballet and aerial dance companies are nonprofit organizations. Since non-profit organizations are able to receive foundational and governmental grant funding, and because circus arts are not amply funded by these entities in the US, there is less incentive for a circus company to be a non-profit. Nevertheless, by acculturating culturally endorsed elements from nouveau cirque, ballet, and aerial dance, Swanson perhaps increases her validation as a circus company in the US.

In contrast, ballet choreographers can appropriate acrobatic and circus elements and have them be considered "high art". A perfect example is the US ballet icon, George Balanchine, appropriating acrobatic and circus aesthetics for his world-renowned NYC Ballet repertory. Not only did Balanchine use acrobatic lines in his work, he also created a "circus" ballet with ballerinas and elephants. ${ }^{29}$ It is ironic that Balanchine's use of circus elements helped make his choreography stand out and achieve a validated status for his company, when in US history, circus has been considered a "low art". The ballet institution holds power in terms of funding and cultural prestige in the US, which has given patrons of ballet the influential authority to determine what is valuable and acceptable as "high art".

The current lineage of aerial dance choreographers in the US is more of a scattered diaspora than a tree. Terry Sendgraff is credited as the founder of aerial dance because she has had the most significant impact on the field of aerial dance. ${ }^{30}$ Nancy Smith was trained in low flying trapeze from Bob Davidson, who was a student of someone who trained with Sendgraff. Smith founded Frequent Flyers ${ }^{\circledR}$ Productions in 1988 and the first international

\footnotetext{
26. Wall, The Ordinary Acrobat, 13.

27. Ibid.

28. Ibid., 283.

29. Stephanie Tuley, "George Balanchine: Europeanist Neoclassicism and the New American Ballet" (lecture, University of Colorado Boulder, October 15, 2014).

30. Bernasconi and Smith, Aerial Dance, 13.
} 
Aerial Dance Festival (ADF) in Boulder in 1999. ADF has provided a venue and educational experience for all types of aerialists and has made aerial dance an internationally known art form. I have been a professional aerial dancer since 2007 and have collaborated with Nancy Smith and other leading aerial dance practitioners in the US that have been students at ADF such as Ninette Paloma (Santa Barbara Centre for Aerial Dance) and Chloe Jensen (Aerial Dance Chicago). I have found that each of these choreographers share Sendgraff's intention of combining dance with an aerial partner to find new mediums of expression, but also cross-over into the realm of circus arts by utilizing circus vocabulary, technique, and apparatuses. However, I have learned from working with these prominent practitioners that they define their work by dance aesthetics and they are inventing unique stylized approaches and apparatuses to untie the dancer from the ground and create individualized aerial dance aesthetics. Both Smith's and Jensen's company websites describe their work both on the ground and in the air as dance, and do not include circus in any of their website descriptions. Paloma was the exception, and until recently, described her artistic intention as:

Our philosophy is quite simple: honor the past and explore the uncharted. Embracing the ancient technique of aerial arts and blending it with the exploratory concept of contemporary movement, SBCAA approaches flight as a metaphor for the human condition. Using inner strength, external emotion, and fluid intention, the magical violet hour between floor and air is continuously blurred, leaving a sweeping smudge over rules that traditionally abound in the worlds of dance and circus. ${ }^{31}$

It is important to note that Paloma recently changed the wording of the last line of the paragraph on the website to include: "the violet hour between floor and air is illuminated, and the architecture of a winged dancer emerges", omitting the reference to circus. ${ }^{32}$ The name of the website has also changed from Santa Barbara Centre for Aerial Arts to Santa Barbara's Conservatory for Floor to Air® Dance. Paloma finds that the US still has a "negative stigma with the circus arts in that they are still somehow lower class, or a lower concept of art". ${ }^{33}$ Although Paloma respects both her circus and dance training, she is clearly making a shift to a more dance-based image that reflects her current artistic voice.

31. "Santa Barbara's Conservatory for Floor to Air® Dance," Santa Barbara Centre for Aerial Dance, accessed October 10, 2014, http://goo.gl/jqDXDw.

32. "Santa Barbara's Conservatory for Floor to Air® Dance," Santa Barbara Centre for Aerial Dance, accessed December 31, 2015, http://goo.gl/jqDXDw.

33. Ninette Paloma, interview by Danielle Garrison, March 17, 2014. 
Aesthetically, aerial circus focuses on the "build up to the trick, and then the 'ta-dah"', whereas aerial dance focus on the transitions and "flow of the movements". ${ }^{34}$ The idea that the dance aesthetic found in aerial dance is superior to the acrobatic aesthetic found in aerial circus is clearly embedded within aerial dance. From my experience, the tension between the two genres rests within both ideas: the belief amongst aerial dance participants that they can appropriate aerial circus technique to train, but transcend the training technique to showcase the artistically superior, physically more tedious, and the less accessible dance aesthetic in their work; on the flipside, aerial circus practitioners claim their genre is more codified than aerial dance and that it is technically superior. The struggle amongst the aerial dance and aerial circus genres to claim a superior ownership of aerial arts, leads aerial dance practitioners to align with dance to maintain a "higher" level on the vertical spectrum of art validation. Again, this debate stems from the idea that dance is art that breeds an intellectual purpose and acrobatics are a craft meant for spectacle. Art prides itself in superseding technique, while craft prides itself purely in the technique. However, even though concert dance and circus have traditionally been divided amongst this line, the line is now distorted and the genres are blending due to their techniques mixing at festivals such as ADF, and as both forms become accessible global practices. Aerial dance and contemporary circus practitioners both embrace the intention to create art that is technically strong, artistically compelling, inventively astute, and intellectually stimulating work that also entertains the public, critics, and funders.

\section{Case Study}

This case study of Aerial Dance Chicago (ADC) reveals the influence of critical review and funding in the validation of aerial dance. ADC has been in flight since 1999 under the direction of Chloe Jensen. Like Terry Sendgraff, Jensen has both a gymnastic and dance background as well as pursued dance at the graduate level. Jensen has had to work hard to prove that ADC is a dance company, rather than a circus troupe. According to Jensen, the work her company does is purely dance that extends dance from the ground into the "vertical dance space". ${ }^{35}$ ADC's website emphasizes that it is a dance company and that its work includes a "strong dance aesthetic" and "transcends the assumed limits of dance". ${ }^{36}$ Jensen's initial work had a more athletic and

34. Bernasconi and Smith, Aerial Dance, 6.

35. Chloe Jensen, telephone interview by Danielle Garrison, September 20, 2014.

36. Chloe Jensen, "Aerial Dance Chicago," Aerial Dance Chicago, accessed September 20, 2014, http://goo.gl/Mmqslc. 
acrobatic aesthetic, reflecting the original name of the company: AMEBA Acrobatic and Aerial Dance (AMEBA). In 2010, Jensen changed the company's name from AMEBA to Aerial Dance Chicago, and as a result, distanced her image from the acrobatic association with aerial arts and clarified her image as dance. I will analyze two critical reviews of Jensen's company: one regarding AMEBA and another involving ADC. The reviews are written by two esteemed Chicago Tribune critics, Lucia Mauro and Laura Molzahn, and demonstrate how the language these influential critics use upholds the hierarchical ballet aesthetic binary.

Language is crucial. How a critic uses language can define a piece, company, or an entire genre. Critics can make, break, and classify a dance company. If a dance company gets a "good" review it can elevate the company's status and allow for greater prominence within its field. The "higher" the status a company is perceived to have within its field, the more it is validated by the local, and often international, dance community. In ADC's 2006 concert "from the Ground Up" (known as AMEBA in 2006) Mauro procures an unfavorable perspective of AMEBA's acrobatic aerial work. Mauro describes the company's work as "airborne circus routines with diverse forms of movement". ${ }^{37}$ Typically, dance critics do not use "routines" to describe specific pieces within a professional dance concert, but by doing so, Mauro is alluding that AMEBA's work does not deserve the traditional language of dance, and downgrades the work to denote unprofessional "circusy" acts. The acrobatic and athletic dancing the company performs is described as "diverse forms of movement"38 and is not even acknowledged as dancing. Mauro is essentially separating and elevating dance from movement, which clearly positions Maruo's preference that ballet-derived movement ascends purely technical and skillful dance technique and is an art, while other types of movement forms are just movement, implying that acrobatic dance requires technique apart from artistic merit, and is therefore a craft. ${ }^{39}$ Mauro continues with this idea and adds "Ameba, overall, is more original in concept than in its actual dance movements - an area where the artists can be more adventurous. Most admirable is the group's desire to downplay the acrobatic tricks in favor of more lucid dancing". 40 The acrobatic aesthetic in AMEBA's work are clearly demoralized by Mauro. By using the word "lucid", the critic begs AMEBA to employ more use of eloquent, articulate, and most importantly: rational, reasonable, established - essentially status quo, traditional, and Western balletic dance - aesthetics in its choreography. The

37. Lucia Mauro, "For Ameba, less can be not enough," Chicago Tribune, July 15 2006, accessed November 13 2014, http://goo.gl/ILjYTY.

38. Mauro, "For Ameba."

39. Homans, Apollo's Angels, 16.

40. Mauro, "For Ameba." 
thread controlled by the traditional Western value system continues to dictate US dance through its critics, influencing Mauro as if she were a puppet, herself performing, in the time of King Louis XIV's reign.

Eight years later, in 2014, following the image and name shift of ADC, Jensen premiered "Surge" in collaboration with Chicago's Elements Contemporary Ballet. This concert was reviewed favorably, even praised and admired by the venerated Chicago Tribune critic, Laura Molzahn, due to ADC's shift to a more ballet aesthetic. The review opens with: "Imagine a huge canvas covered in human flesh and billowing cloth, combining Hieronymus Bosch's earthbound creatures with the angels of Michelangelo's 'Last Judgment'". ${ }^{41}$ The opening vision of this collaboration is compared to two venerated pieces of Renaissance art, reinforcing the tether and current validation between Renaissance Neoplatonic ideals and Louis XIV's aesthetic taste. Unlike in Mauro's review, according to Molzahn there is no confusion as to what exactly ADC is; ADC is an aerial dance company. Molzahn esteems that "(a)erial dance and ballet on the same stage is a genius move" as their "technique is similar, with extended limbs and taut torso, and so is the aim: to go beyond the human body and everyday life, to approach the magical, even the eternal".42 Again, Molzahn's language depicts the influence of the Neoplatonic ideals and "higher" purpose of dance fashioned by Louis XIV. According to Molzahn, not only is this pairing aesthetically "correct", but when conjoined, these genres have the ability to transcend humanity's earthly bounds and access immortality. Since the reign of Louis XIV, ballet has vertically positioned itself to reach the heavens, and with the addition of aerial work (aligned with ballet's aesthetic goals) the dancer can now actualize its mission to ascend from the earth into the heavenly realm, and truly emulate a Michelangelo painting.

"Surge" presents success for ADC on various levels. Not only was this collaboration acclaimed by a highly respected Chicago critic, the collaboration with a leading contemporary ballet company was also an official acceptance by the highly artistic and highly exclusive Chicago dance community - a community Jensen has been trying to become a member of for many years. The less aesthetically "confused" ADC becomes, and as it sheds the acrobatic and aerial circus qualities it once possessed, the more it gains ground in the Chicago dance scene. Although, Jensen claims "within the context of the contemporary dance work and contemporary ballet work, we actually still incorporate some highly acrobatic elements, not as flashy 'tricks', but as a

41. Laura Molzahn, "'Silk and Steel' at North Shore Center for the Performing Arts," Chicago Tribune, July 20, 2014, accessed September 20, 2014, http://goo.gl/d1SL1z.

42. Molzahn, "Silk and Steel." 
highly physical means of expression".43 Consequently, as ADC is now a "high art" dance company using acrobatic elements for an artistic purpose, just as Balanchine did, the use of acrobatics is deemed "acceptable". When this virtuosic collaboration took flight and Molzahn's language in her review solidified ADC's place in the Chicago dance community, it validated not only ADC but also the genre of aerial dance in Chicago.

In addition to the successful review and ballet collaboration that provided ADC validation within the Chicago dance community, ADC also received more funding when it became identified as a dance company. In an email interview Jensen claims: To one particular foundation, I wrote grant proposals for six consecutive years without a positive funding response. In the year they funded ADC, I was required to submit an extra statement with regard to our work, that we did not participate in circus arts activity, but rather were fully focused on our work from a dance perspective. ${ }^{44}$

This particular foundation would not fund ADC because of its appearance as "circusy". As ADC became less visually acrobatic and more balletic, Jensen received palpable rewards for aligning her aesthetic with contemporary ballet, and gained validity through critical notoriety and funding. What does this mean for the rest of the aerial dance community?

\section{Conclusions}

The language of critics holds the power to influence funders and academia, as critical reviews are cited in and provide evidence of cultural value for grant-writing and research. Unfortunately, if aerial dance practitioners, including myself, are steered to create choreography to fit a particular aesthetic deemed worthy by critics, academics, and funders, then the pioneering creativity, ingenuity, and un-feared navigation that compose the essence of aerial dance afforded by its adolescent age is lost; inventive ambitions imitate what has already been done through dance. We need to make sure our work is in constant search of what is authentic for ourselves and utilizes the untouched potential of aerial dance while remaining inspired by its possibility of rebellion. That is not to say our work cannot be in conversation with tradition, as recognizing and embracing our roots is imperative, but we should look beyond those confines to explore a unique potential for aerial dance. Critical and financial success are important for the longevity of aerial dance companies, but we cannot let either dictate our artistic productions or cloud our artistic visions. Why does a current new US genre need to conform to what the "gatekeepers", who are dogmatically

43. Chloe Jensen, email interview by Danielle Garrison, November 30, 2014. 44. Ibid. 
aligned with Christian and Neoplatonic artistic ideals, validate as appropriate? Funding organizations and critics should consider their role in determining validation for the arts, and reconsider their values and why they are maintained. Although CU-Boulder is making strides by supporting aerial dance, there needs to be discussion as to why aerial dance is part of a graduate-level degree program while circus is currently not. Maybe the US arts academy needs to look to France as a model, which birthed ballet, aerial circus, and the binary between dance and acrobatics, but has figured out how to support both, in order to reposition our artistic value system from a vertical alignment to a horizontal spectrum. Aerial arts cannot be claimed as having a superior ownership by either the aerial dance or aerial circus genre, but rather the differences of each genre should be acknowledged and celebrated. It is time to redefine what has been defined as "high art" since 1661. Art academics, critics, funders, and most importantly, practitioners, should deconstruct vertical hierarchical notions and set an example for society by being beacons of visionary creativity on a horizontal value continuum. Jensen eloquently states: I think the value of art though, besides being entertaining is that it inspires and enlivens us, makes us think, feel, move, create, connect with each other, and when it is really good, has the potential to shift our perspectives and open our minds. Any art that does these things, in my opinion should be valued, and funded within our communities. 45

Aerial dance can be art that is unchained by vertical ideology and find expression in the three-dimensional realm while achieving what human beings have always tried to do through art: transcend the constraints of our humanity and explore unbound possibility.

\section{Bibliography}

"Aloft." Aloft Circus Arts. Accessed September 27, 2014. http://goo.gl/qNiCtF.

"Aloft Circus Arts." Aloft Circus Arts. Accessed November 1, 2014. http://goo.gl/1spp3Y.

Benjamin, Adam. Making an Entrance: Theory and Practice for Disabled and NonDisabled Dancers. London: Routledge, 2002.

Bernasconi, Jayne C., and Smith, Nancy E. Aerial Dance. Champaign: Human Kinetics, 2008.

Hatfield, Rab. "Some Misidentifications in and of Works by Botticelli." In Sandro Botticelli and Herbert Horne New Research, edited by Rab Hatfield. Florence: Syracuse University Press, 2009.

45. Chloe Jensen, email interview by Danielle Garrison, December 31, 2015. 
Homans, Jennifer. Apollo's Angels. New York: Random House, 2010.

Jensen, Chloe. "Aerial Dance Chicago." Aerial Dance Chicago. Accessed September 20, 2014. http://goo.gl/Mmqslc.

Mauro, Lucia. "For Ameba, less can be not enough." Chicago Tribune, July 15, 2006. Accessed November 13, 2014. http://goo.gl/ILjYTY.

Molzahn, Laura. '"Silk and Steel' at North Shore Center for the Performing Arts." Chicago Tribune, July 20, 2014. Accessed September 20, 2014. http://goo.gl/cRhyC8.

"Santa Barbara's Conservatory for Floor to Air® Dance." Santa Barbara Center for Aerial Dance. Accessed October 10, 2014. http://goo.gl/jqDXDw.

"Santa Barbara's Conservatory for Floor to Air ${ }^{\circledR}$ Dance," Santa Barbara Centre for Aerial Dance, accessed December 31, 2015. http://goo.gl/jqDXDw.

Tuley, Stephanie. "George Balanchine: Europeanist Neoclassicism and the New American Ballet." Lecture given at the University of Colorado Boulder, October 15, 2014.

Wall, Duncan. The Ordinary Acrobat. New York: Vintage Books, 2013. 
